\title{
Tinjauan Penatalaksanaan Program Indonesia Sehat Dengan Pendekatan Keluarga (PIS-PK) Pada Puskesmas Tegal Sari Tahun 2019
}

\author{
Terry Noviar Panggabean
}

Program Studi D-IV Manajemen Informasi Kesehatan, Universitas Imelda Medan

\begin{tabular}{l} 
Article Info \\
\hline Article history: \\
Received Feb17, 2020 \\
Revised Feb26, 2020 \\
Accepted Feb28, 2020 \\
\hline
\end{tabular}

Keywords:

PIS-PK

Public Health Center

Aplication

\begin{abstract}
ABSTRAK
In essence, health development is a variety of efforts or efforts carried out by each individual of the Indonesian Nation in the aim of increasing the awareness of the Indonesian people, the willingness, and the ability to live a healthy life for every individual of Indonesia, to realize the high degree of public health, which is also an investment for development socially and economically productive human resources. The purpose of this study was to determine the extent of healthy Indonesian program management at the Tegal Sari Health Center. This type of research uses descriptive methods. When the study was conducted in March to May 2019 and the study was conducted at the Puskesmas Tegal Sari Medan. Data collected using observation. The results showed the data collected to date were 5,500 families, and data entered in healthy family applications were 3,762 families. Whereas many families in the work area of Tegal Sari Health Center are 7,483 families. It is recommended to the Puskesmas to increase the number of human resources and facilities in working on this program, improving the internet connection network.
\end{abstract}

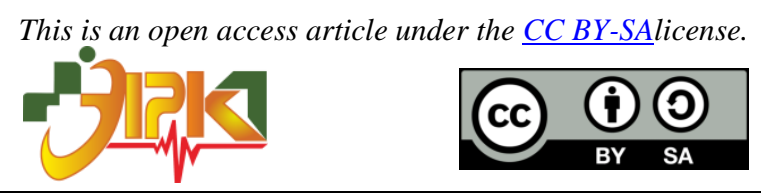

\section{Corresponding Author:}

Terry Noviar Panggabean,

Program Studi D-IV Manajemen Informasi Kesehatan,

Universitas Imelda Medan,

Jl. Bilal No. 52 Kelurahan Pulo Brayan Darat I Kecamatan Medan Timur, Medan - Sumatera Utara.

Email: tmm.panggabean@gmail.com

\section{PENDAhuluan}

Angka kesakitan dan kematian merupakan indikator dalam menilai derajat kesehatan masyarakat. Penyakit Tidak Menular (PTM) melambangkan pemicu satu-satunya kematian secara menyeluruh. Di Indonesia beberapa Pemicu kematian masih di pengaruhi dan disebabkan dari Penyakit Tidak Menular (Kemenkes, 2017). Adapun yang menjadi dasar dari data SKRT 1995, SKRT 2001, dan Riskesdas 2007, proporsi Penyakit Tidak Menular (PTM) mengalami naiknya peningkatan dari tahun 1995-2007 yaitu dari dimulai dari angka empat puluh satu koma tujuh persen meningkat menjadi lima puluh Sembilan koma lima persen (Kemenkes, 2012). Didasari oleh Profil Kesehatan Provinsi Sumatera Utara pada tahun 2016, beberapa jumlah kasus seperti hipertensi di wilayah Provinsi Sumatera Utara dan sekitarnya terdapat sebanyak 334.230 kasus, Sedangkan di wilayah Kota Medan dan sekitarnya merupakan wilayah dengan jumlah hipertensi tertinggi di Provinsi Sumatera Utara sebanyak 59.541 kasus. 
Di dalam hakekatnya pembangunan kesehatan merupakan berbagai usaha ataupun upaya yang dilaksanakan oleh setiap Individu Bangsa Indonesia dalam tujuan meningkatkan kesadaran masyarakat indonesia, kemauan, serta kemampuan hidup yang sehat bagi setiap individu Bangsa Indonesia agar terwujud tingginya derajat kesehatan masyarakat, yang juga melambangkan suatu masukan teruntuk pembangunan sumber daya manusia secara merata yang berguna dalam bidang sosial dan ekonomis. Keberhasilan setiap pembangunan penentuannya dalam bidang kesehatan disertai oleh kesetimbangan antar upaya program dan sektor, serta kesetimbangan dengan usaha-usaha yang telah terlaksana dari rentang waktu sebelumnya (Menkes, 2015).

Meneladani dari Undang-undang No.23 Republik Indonesia Tahun 2014 tentang Pemerintahan Daerah dikemukakan bahwa defenisi Pembangunan keluarga adalah suatu upaya ataupun usaha agar terwujudnya suatu keluarga yang berkualitas dalam hidupnya dipengaruhi oleh lingkungan yang sehat. Ada lima fungsi keluarga menurut Friedman (1998), salah satunya merupakan fungsi dari keperawatan atau pemeliharaan kesehatan (The Health Care Function). Untuk menggapai dan mempertahankan keadaan kesehatan anggota keluarga agar tetap memiliki produktivitas yang tinggi adalah merupakan salah satu fungsinya. Salah satu tugas keluarga di bidang kesehatan yaitu pengembangan dalam fungsi di atas. Keadaan kesehatan yang dipertahankan mencakup pencegahan, perawatan, pemeliharaan, termasuk upaya membangun hubungan yang saling timbal balik antara keluarga dengan fasilitas kesehatan.

Dalam pencapaian tujuannya dalam Pusat Kesehatan Masyarakat melakukan berbagai macam program diatur dalam Keputusan Menteri Kesehatan RI Nomor HK.02.02/Menkes/52/2015. Salah satu programnya yaitu Program Indonesia Sehat melalui Pendekatan Keluarga (PIS-PK) dengan aplikasi Keluarga Sehat.

Bidik misi dari Program Indonesia Sehat adalah meningkatnya derajat kesehatan dan status gizi masyarakat melalui upaya kesehatan dan pemberdayaan masyarakat yang didukung dengan perlindungan finansial dan pemerataan pelayanan kesehatan. Bidik misi ini sesuai dengan sasaran pokok RPJMN 2015-2019, yaitu (Menkes, 2015) :

1. Naiknya tingkat status kesehatan dan gizi ibu dan anak.

2. Berangsur naiknya tingkat pengendalian penyakit.

3. Peningkatan jalan masuk dan mutu pelayanan kesehatan dasar dan rujukan paling utama di daerah jauh dan terpencil, di daerah yang tertinggal dan di daerah dekat perbatasan.

4. Terjadinya peningkatan terhadap area pelayanan kesehatan secara menyeluruh melalui Kartu Indonesia Sehat (KIS) dan kualitas akan pengelolaan SJSN kesehatan.

5. Terlaksananya dan tercukupinya kebutuhan akan petugas di bidang kesehatan, obat-obatan dan tersedianya vaksin, serta

6. Terjadinya peningkatan akan responsivitas sistem kesehatan.

Terlaksananya Program Indonesia Sehat digagas dengan menjejakkan tiga tiang utama, yaitu :

1. Menerapkan cara ataupun pola hidup sehat.

2. Meningkatkan penguatan akan pelayanan di bidang kesehatan, dan

3. Terlaksananya sistem Jaminan Kesehatan Nasional (JKN) yang dilaksanakan secara terpadu.

Perlakuan penerapan paradigma sehat dilakukan dengan disusunnya suatu strategi kesehatan dalam bidang pembangunan, penguatan upaya secara promotif dan preventif, serta pemberdayaan masyarakat per tiap individu. Berbagai penguatan pelayanan dalam sector kesehatan dilakukan dengan menyusun strategi peningkatan akses kepelayanan kesehatan, optimasi sistem rujukan, dan peningkatan mutu menggunakan pendekatan asuhan berkesinambungan dan intervensi berbasis risiko kesehatan. Sedangkan perlakuan 
pelaksanaan JKN dengan disusunnya strategi perluasan sasaran dan manfaat (benefit), serta berupaya dalam kendali mutu dan biaya. Tercapainya keluarga-keluarga yang sehat merupakan semua aspek yang telah dijelaskan di atas. (Menkes, 2015).

Aplikasi keluarga sehat adalah salah satu cara Puskesmas untuk meningkatkan jangkauan sasaran dan mendekatkan/meningkatkan akses pelayanan kesehatan di wilayah kerjanya dengan mendatangi keluarga. Puskesmas tidak hanya menyelenggarakan pelayanan kesehatan di dalam gedung, melainkan juga keluar gedung dengan mengunjungi keluarga di wilayah kerjanya, (Permenkes, 2016).

Berdasarkan survei pendahuluan Puskesmas Tegal Sari sudah melakukan Program Indonesia Sehat melalui Pendekatan keluarga (PIS-PK) dengan menggunakan aplikasi dari PIS-PK yaitu Aplikasi Keluarga Sehat, dimulai dari juli 2017. Pendataan yang telah dilakukan dengan mengunjungi rumah masyarakat per keluarga sebanyak 5500 keluarga dan data yang telah di entri dalam Aplikasi Keluarga sehat sebanyak 3762 keluarga. Sedangkan banyak keluarga dalam area kerja Puskesmas Tegal Sari sebanyak 7483 keluarga. PIS-PK sudah dilaksanakan selama dua tahun ini.

Kementerian Kesehatan, Dinas Kesehatan Provinsi, Dinas Kesehatan Kabupaten/Kota dan Puskesmas dalam melakukan monitoring dan evaluasi perkembangan kesehatan masyarakat melalui program aplikasi keluarga sehat yang bertujuan untuk, yaitu:

1. Tujuan Umum

a. Sebagai acuan bagi Kementerian Kesehatan Dinas Kesehatan Provinsi, Dinas Kesehatan Kabupaten/Kota dan Puskesmas dalam melakukan monitoring dan evaluasi kesehatan masyarakat dan keluarga.

b. Meningkatkan akses keluarga terhadap pelayanan kesehatan komprehensif, meliputi pelayanan promotif dan preventif serta pelayanan kuratif dan rehabilitatif dasar.

c. Mendukung pencapaian Standar Pelayanan Minimum (SPM) Kabupaten/Kota dan SPM Provinsi, melalui peningkatan akses dan skrining kesehatan.

d. Mendukung pelaksanaan Jaminan Kesehatan Nasional (JKN) dengan meningkatkan kesadaran masyarakat untuk men-jadi peserta JKN.

e. Mendukung tercapainya tujuan Program Indonesia Sehat dalam Rencana Strategis Kementerian Kesehatan Tahun 2015 - 2019.

2. Tujuan Khusus

a. Mendapatkan informasi tentang kesehatan dan sejarah penyakit (penyakit keturunan/menular) dari masyarakat.

b. Mendapatkan informasi tentang kemajuan pelaksanaan PIS - PK

c. Menilai keberhasilan PIS - PK dalam suatu periode tertentu, sudah sejauh mana tiap provinsi melakukan pelaksanaan PIS- PK

d. Meningkatkan pembinaan keluarga secara terintegrasi dan berkesinambungan

e. Meningkatkan komitmen daerah dalam pelaksanaan PIS - PK

f. Meningkatkan pencapaian target sasaran keluarga sehat

g. Membangun hubungan yang baik antar petugas kesehatan dan masyarakat melalui kunjungan petugas kesehatan ke tiap rumah keluarga.

h. Memberi umpan balik implementasi PIS - PK (Kemenkes,2016).

Dalam rangka pelaksanaaan Program Indonesia Sehat telah disepakati adanya 12 indikator utama untuk penanda status kesehatan sebuah keluarga. Kedua belas indikator utama tersebut adalah sebagai berikut:

1. Keluarga mengikuti program Keluarga Berencana (KB)

2. Ibu melakukan persalinan di fasilitas kesehatan

3. Bayi mendapat imunisasi dasar lengkap

4. Bayi mendapat air susu ibu (ASI) eksklusif

5. Balita mendapatkan pemantauan pertumbuhan 
6. Penderita tuberkulosis paru mendapatkan pengobatan sesuai standar

7. Penderita hipertensi melakukan pengobatan secara teratur

8. Penderita gangguan jiwa mendapatkan pengobatan dan tidak ditelantarkan

9. Tidak diperkenankan ada anggota keluarga yang merokok.

10. Seluruh anggota keluarga harus sudah menjadi anggota Jaminan Kesehatan Nasional (JKN)

11. Akses air bersih harus sudah dipunyai oleh keluarga

12. Keluarga mempunyai akses atau menggunakan jamban sehat (Kemenkes, 2016).

Dari permasalahan diatas, penulis tertarik untuk mengetahui sejauh mana Program Indonesia Sehat Pendekatan Keluarga (PIS-PK) di Puskemas Tegal Sari Medan dengan mengambil judul "Tinjauan Penatalaksanaan Program Indonesia Sehat Dengan Pendekatan Keluarga (PIS-PK) Pada Puskesmas Tegal Sari Tahun 2019”.

\section{METODE PENELITIAN}

A. Jenis Penelitian

Penelitian ini adalah penelitian deskriptif yang bertujuan untuk mengetahui penatalaksanaan program Indonesia sehat dengan pendekatan keluarga di sebuah Puskemas. Menurut Notoatmodjo (2010), metode penelitian deskriptif adalah sesuatu metode penelitian deskriptif yang dilakukan dengan bertujuan untuk mendeskripsikan tentang suatu keadaan secara objektif. Metode penelitian ini digunakan untuk memecahkan atau menjawab permasalahan yang sedang dihadapi pada situasi sekarang. Variabel adalah ciri, sifat atau ukuran yang dimiliki atau didapatkan oleh satuan penelitian tentang sesuatu konsep pengertian tertentu (Notoatmodjo, 2010).

B. Variabel Penelitian

Untuk membatasi ruang linkup atau pengertian variabel-variabel yang diteliti/diamati, perlu sekali variabel-variabel tersebut diberi batasan atau defenisi operasional (Notoatmodjo, 2010).

Dengan memperhatikan latar belakang dan perumusahan penelitian tersebut, maka defenisi operasional variabel dari penelitian ini adalah sebagai berikut:

1. Lingkungan fisik yaitu lingkungan hidup yang meliputi segala sesuatu di sekitar petugas program indonesia sehat

2. Peran dan tugas yaitu serangkaian hak, kewajiban, harapan, norma dan perilaku seseorang yang harus dihadapi dan dipenuhi.

C. Analisis Data

Analisis data digunakan untuk menyederhanakan data kedalam bentuk yang lebih mudah dibaca dan dimengerti. Analisis data dilakukan secara deskriptif dengan melihat presentasi data yang telah terkumpul disajikan dalam tabel distribusi frekuensi yang kemudian dilanjutkan dengan membahas hasil penelitian dengan menggunakan teori kepustakaan yang ada dan dapat diperoleh suatu kesimpulan.

\section{HASIL DAN PEMBAHASAN}

\subsection{Hasil}

Cara peng-aplikasi-an/ penggunaan aplikasi keluarga sehat, yaitu:

1. Pada bagian ini dilakukan proses login. Untuk menampilkan menu login ini, pengguna harus terlebih dahulu mengakses aplikasi keluarga sehat 


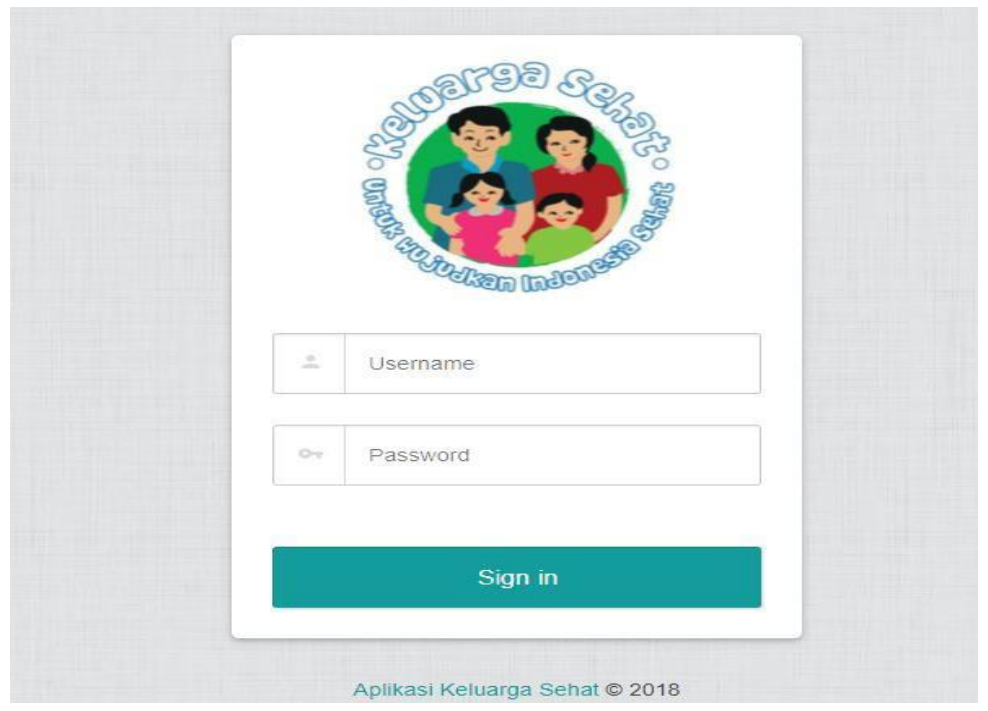

Gambar 1. Halaman Login PIS-PK

2. Setelah berhasil login maka aplikasi akan menampilkan menu yang disesuaikan dengan hak akses yang dimiliki oleh pengguna yang sedang login tersebut. Untuk grup pengguna (aktor), dapat mengakses semua akun pengguna yang masuk dalam grup pengguna

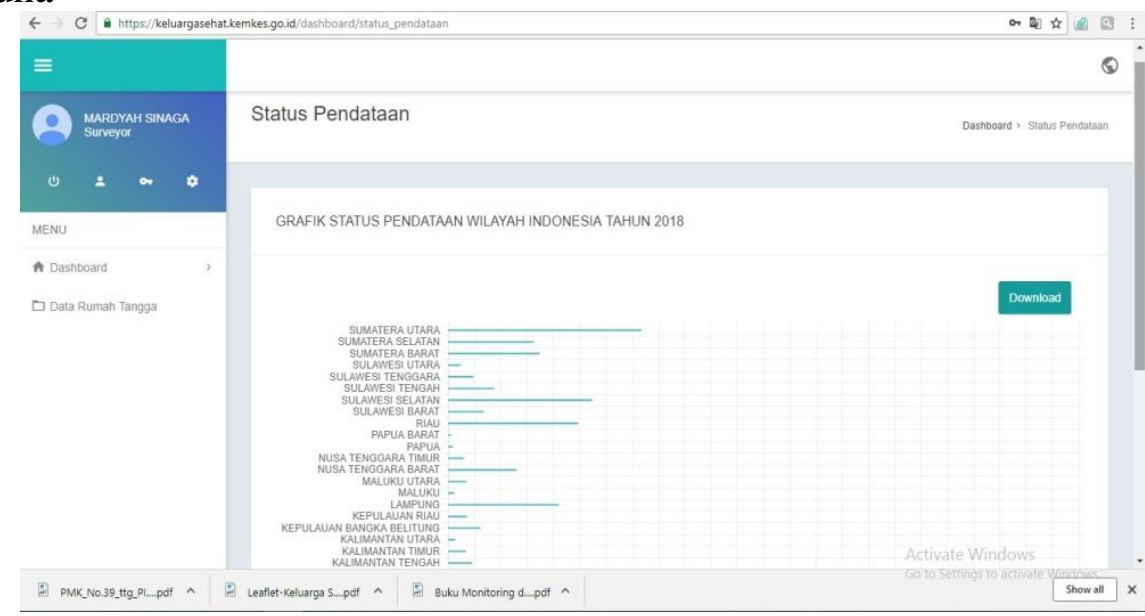

Gambar 2. Halaman Status Pendataan

3. Setelah muncul tampilan seperti diatas, maka klik data rumah tangga di pojok kiri.

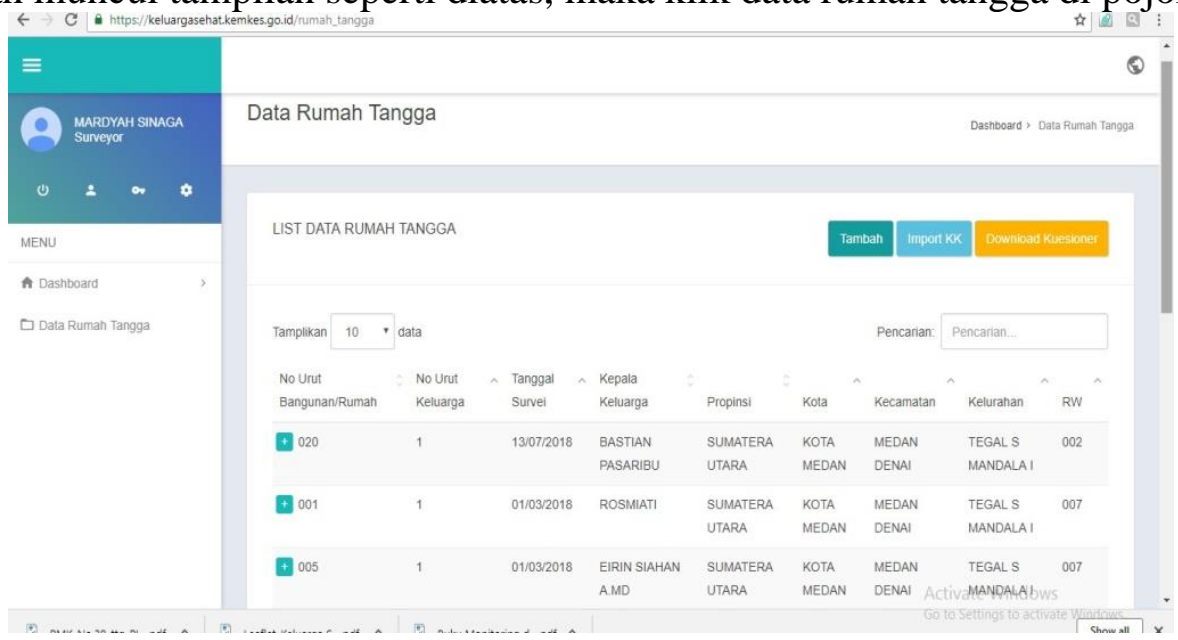

Gambar 3. Halaman Data Rumah Tangga 
4. Setelah muncul tampilan di atas, lalu klik "tambah" sebelah kanan.

5. Maka akan muncul tabel/data yang akan di isi oleh petugas pelayanan kesehatan.

\subsection{Pembahasan}

Luas wilayah kerja dari Puskesmas tegal sari adalah $87 \mathrm{Ha}$, yang memiliki 2 kelurahan, dan 27 lingkungan. Jumlah penduduk dalam wilayah kerja Puskesmas tegal sari sebanyak 42.749 jiwa, terdiri dari 21.047 pria, 21.702 wanita, dan jumlah KK sebanyak 12.047. Pendataan keluarga dilakukan dengan mengunjungi rumah setiap keluarga yang ada dalam lingkungan area kerja Puskesmas Tegal Sari dan petugas pelayanan kesehatan mengisi kuesioner yang telah di sediakan oleh pemerintah dalam PIS-PK dengan aplikasi keluarga sehat (kuesioner ada dalam lampiran). Adapun cara pengumpulan data untuk pengisian data di Aplikasi keluarga Sehat, yaitu:

1. Persiapan kuisioner, alat tulis, dan keperluan lain yang dibutuhkan untuk pengisian data per keluarga, yang akan di bawa pada saat berkunjung ke rumah-rumah warga/ masyarakat.

2. Tiap keluarga menyiapkan fotocopy kartu keluarga sebagai identitas tiap keluarga.

3. Keluarga akan di tanyai satu per satu sesuai dengan isi kuesioner yang telah disediakan dalam aplikasi keluarga sehat.

4. Setelah data terisi, petugas pelayanan kesehatan berbagi informasi kepada masyarakat yang dikunjungi sebagai bagian dari promotif dan preventif.

5. Setelah petugas selesai melakukan pendataan dan kunjungan ke tiap-tiap rumah warga/masyaarakat, petugas pelayanan kesehatan dapat meng-entry data yang telah terkumpul dalam Aplikasi keluarga Sehat.

Pelaksanaan PIS-PK di Puskesmas Tegal Sari masih belum optimal, dimana data yang seharusnya terkumpul harus sesuai dengan jumlah keluarga yang ada dalam area kerja puskesmas. Data yang terkumpul hingga saat ini adalah 5.500 keluarga, dan data yang dientri dalam aplikasi keluarga sehat sebanyak 3.762 keluarga. Sedangkan banyak keluarga dalam area kerja Puskesmas Tegal Sari sebanyak 7.483 keluarga.

Puskesmas Tegal Sari sudah melaksanakan Program PIS-PK dari juli 2017, penyajian data agregat Indikator Keluarga Sehat (IKS) berbasis kewilayahan yang dilakukan oleh petugas pelayanan kesehatan (surveyor tingkat lapangan yang berkunjung ke rumah-rumah warga/masyarakat), dan di pantau pelaksanaannya oleh Kepala Puskesmas dengan memperhatikan kondisi infrastruktur di Indonesia baik di tingkat pusat maupun tingkat daerah / lapangan.

\section{KESIMPULAN}

Puskesmas Tegal Sari sudah melakukan Program Indonesia Sehat melalui Pendekatan keluarga ( PIS-PK) dengan menggunakan aplikasi dari PIS-PK yaitu Aplikasi Keluarga Sehat, dimulai dari juli 2017. Pendataan yang telah dilakukan dengan mengunjungi rumah masyarakat per keluarga sebanyak 5.500 keluarga dan data yang telah di entri dalam Aplikasi Keluarga sehat sebanyak 3.762 keluarga.

Namun pelaksanaan PIS-PK di Puskesmas Tegal Sari masih belum optimal, dimana data yang seharusnya terkumpul dalam satu tahun harus sesuai dengan jumlah keluarga yang ada dalam area kerja puskesmas. Data yang terkumpul hingga saat ini adalah 5.500 keluarga, dan data yang dientri dalam aplikasi keluarga sehat sebanyak 3.762 keluarga. Sedangkan banyak keluarga dalam area kerja Puskesmas Tegal Sari sebanyak 7.483 keluarga. PIS-PK sudah dilaksanakan selama satu tahun ini.

Puskesmas Tegal Sari melaksanakan Program PIS-PK dari juli 2017, penyajian data agregat Indikator Keluarga Sehat (IKS) berbasis kewilayahan yang dilakukan oleh petugas pelayanan kesehatan (surveyor tingkat lapangan yang berkunjung ke rumah-rumah 
warga/masyarakat), dan di pantau pelaksanaannya oleh Kepala Puskesmas dengan memperhatikan kondisi infrastruktur di Indonesia baik di tingkat pusat maupun tingkat daerah / lapangan.

Adapun cara pengumpulan data untuk pengisian data di Aplikasi keluarga Sehat, yaitu:

1. Persiapan kuisioner, alat tulis, dan keperluan lain yang dibutuhkan untuk pengisian data per keluarga, yang akan di bawa pada saat berkunjung ke rumah-rumah warga/ masyarakat.

2. Tiap keluarga menyiapkan fotocopy kartu keluarga sebagai identitas tiap keluarga.

3. Keluarga akan di tanyai satu per satu sesuai engan isi kuesioner yang telah disediakan dalam aplikasi keluarga sehat.

4. Setelah data terisi, petugas pelayanan kesehatan berbagi informasi sebagai bagian dari promotif dan preventif.

5. Setelah petugas selesai melakukan pendataan dan kunjungan ke tiap-tiap rumah warga/masyaarakat, petugas pelayanan kesehatan dapat meng-entry data yang telah terkumpul dalam Aplikasi keluarga Sehat.

\section{REFERENCES}

Dinas Kesehatan Provinsi Sumatera Utara. 2016. Profil Kesehatan Provinsi Sumatera Utara Tahun 2016. Medan.

Efendi. (2009). Manajemen Pusat Kesehatan Masyarakat. Jakarta : Salemba Medika.

Efendi, Ferry \& Makhfud. (2009). Keperawatan Kesehatan Komunitas Teori dan Praktik dalam Keperawatan. Jakarta : Salemba Medika. Friedman. 1998. Keperawatan Keluarga. Jakarta: EGC.

Kemenkes RI. 2012. Profil Data Kesehatan Indonesia Tahun 2011. Jakarta : Kemenkes RI.

Kemenkes RI, 2015. Peraturan Menteri Kesehatan Nomor HK.02.02/Menkes/52/2015tentang PIS - PK. Jakarta: Kemenkes RI.

Kemenkes RI, 2016. Peraturan Menteri Kesehatan Nomor. 39 tahun 2016 tentang Pedoman Penyelenggaraan Program Indonesia Sehat dengan Pendekatan Kelarga.

Kemenkes RI, 2017. Pedoman Monitoring dan Evaluasi Pelaksanaan Program Indonesia Sehat dengan Pendekatan keluarga (PIS - PK). Jakarta: Kemenkes RI.

Notoatmodjo. 2010. Metodologi Penelitian Kesehatan. Jakarta : Rineka Cipta.

Notoatmodjo. 2012. Metodologi Penelitian Kesehatan. Jakarta: Rineka Cipta.

Saryono. 2013. Metodelogi penelitian kualitatif dan kuantitatif dalam bidang kesehatan. Yogyakarta: Nuha Medika.

Trihono. 2005. Manajemen Puskesmas Berbasis Paradigma Sehat. Jakarta: CV Sagung Seto.

Trihono. 2010. Riset Kesehatan Dasar : Badan Penelitian dan Pengembangan Kesehatan Departemen Kesehatan Republik Indonesia. Jakarta, Indonesia.

Undang-Undang Nomor 23 Tahun 2014 Tentang Pemerintahan Daerah 


\section{BIOGRAPHIES OF AUTHORS}

\begin{tabular}{l|l} 
Terry Noviar Panggabean, Gelar Sarjana diperoleh dari STMIK Logika, Jurusan \\
Teknik Informatika pada Tahun 2011. Magister Ilmu Komputer diperoleh dari \\
Universitas Sumatera Utara pada Tahun 2016. Saat ini aktif sebagai pengajar di Program \\
Studi D-IV Manajemen Informasi Kesehatan Universitas Imelda Medan.
\end{tabular}

